\title{
Development and Standardization of Knowledge Test for Organic Waste Management
}

\author{
Amandeep Singh ${ }^{1 *}$, Rupasi Tiwari ${ }^{2}$, Pratikshya Panda ${ }^{1}$, Pragya Joshi $^{1}$ and Triveni Dutt ${ }^{3}$ \\ ${ }^{1}$ Division of Extension Education, ICAR-Indian Veterinary Research Institute, Izatnagar, \\ Bareilly, Uttar Pradesh-243122, India \\ ${ }^{2}$ Agricultural Technology Information Centre, ICAR-Indian Veterinary Research Institute, \\ Izatnagar, Bareilly, Uttar Pradesh-243122, India \\ ${ }^{3}$ ICAR-Indian Veterinary Research Institute, Izatnagar, Bareilly, Uttar Pradesh-243122, India \\ *Corresponding author
}

\section{A B S T R A C T}

\begin{tabular}{|l|}
\hline K e y w o r d s \\
Aiken's coefficient, \\
Cronbach's alpha, \\
Knowledge test, \\
Organic waste, \\
Reliability, Validity
\end{tabular}

Majority of the organic waste in India is not disposed properly due to the lack of knowledge and an important resource gets wasted likewise. Therefore, a tool in the form of knowledge test was developed and standardized for measuring the knowledge of stakeholders regarding organic waste management. A total number of 102 items were collected in the form of open-ended and multiple choice questions which were served to 36 farmers for their response. Data were analyzed for calculating difficulty and discrimination index and 26 items falling between the difficulty index of 30 to 80 and discrimination index of 0.30 to 0.55 were selected for calculating reliability and validity. Split-half reliability was calculated using Spearman Brown Prophecy Formula and was found to be 0.927. The Cronbach's Alpha was calculated to be 0.828 and was significant $(\mathrm{p}<0.05)$. Validity of the test was calculated using Aiken's Coefficient (V Coefficient) for individual items, which was more than 0.80 for all the items $(\mathrm{p}<0.05)$. Therefore, the final knowledge test containing 26 items related to agricultural, household and livestock waste was standardized. The test can be used for assessing the knowledge gap of the stakeholders for organic waste management and suitable interventions can be made for enhancing the knowledge, thus converting the organic waste to wealth.

\section{Introduction}

Waste generated in rural areas is organic in nature, thus making its handling much easier. This waste does not cause much harm as it can be managed easily by composting and other simpler waste management protocols. Rural areas contribute 0.3 to 0.4 million tonnes (MT) of waste per day which leads to the production of 109.5 MT per year (Ministry of Drinking Water and Sanitation, 2015). According to Singh (2019), only 56.19 percent of the organic waste gets utilized in the rural areas for which the major deterrent for less utilization was low level of knowledge regarding organic waste management among respondents. Therefore, knowledge have direct impact on the utilization of organic waste. 
Vyas and Maheshwari (2009) have stated that the success or failure of any programme or practice, mainly depends upon the people's awareness and knowledge towards innovations, hence making it essential to quantitatively determine the knowledge level of stakeholders before initiating any developmental work.

According to modern definition of knowledge by Oxford Dictionary, knowledge is a familiarity, awareness or understanding, of someone or something, such as facts, information, description or skills, which is acquired through experience or education by perceiving, discovering or learning. Kerlinger (1964) defined test as a systematic procedure in which the individual tested is presented with a set of constructed stimuli to which he responds, the responses enables the tester to make inference about the intended trait. Whereas knowledge test can be defined as an instrument of measurement for measuring the present proficiency, mastery and understanding of general and specific areas of knowledge. Therefore, to find out the knowledge level of respondents regarding organic waste management, knowledge test on organic waste management was developed and standardized.

\section{Materials and Methods}

The knowledge test was developed according to the methodology given by Edwards (1957).According to Garret (1966) 'any test contains problems or tasks graded in difficulty from very easy to very hard by known steps or intervals'. These problems or tasks are referred as test items. Items for the test were compiled through literature, discussions with field extension personnel, subject matter specialists, academicians and with the researcher's own experience. According to criteria laid by Edwards (1957), 102 items were initially selected encompassing major areas of organic waste management. The items selected were according to the level of knowledge and understanding of the dairy farmers. A knowledge check was prepared with these 102 items for administering them to the farmers for item analysis and screening out non-relevant and weak items. Correct replies for the items were ascertained in consultation with the literature and specialists to prepare a key. Knowledge check was administered to 36 dairy farmers of village Naiwala and Thickriwala of block Barnala in the nonsample area (Barnala district). The responses were quantified by giving a score of one (1) to the correct response and zero (0) to the incorrect response or in case farmers do not know the answer. Thus, total number of correct answers rendered by an individual was the knowledge score secured by him. Thus, the range of obtainable score was 0-102.

Item analysis was carried out using difficulty and discrimination index. The item analysis of a test usually yields two kinds of information, i.e. the item difficulty and item discrimination. The index of the item difficulty reveals how difficult the item is; whereas the index of discrimination indicates the extent to which an item discriminates the well-informed farmer from the poorly informed ones. After calculating the score obtained by 36 respondents, the scores were arranged in a descending order.

These 36 respondents were then divided into six equal groups, each having six respondents. Respondents in each group have been arranged in descending order according to the score obtained by each one of them. These groups were named as G1, G2, G3, G4, G5 and G6 respectively. For item analysis, the middle two groups, i.e., G3 and G4 were eliminated. Only four extreme groups with high and low scores have been considered for computation of item difficulty and their discrimination indices. 
The difficulty index was measured in terms of percentage of incorrect responses obtained for a particular question. This was calculated by using the formula:

$P_{i}=\frac{n_{i}}{N_{i}} \times 100$

Where,

$P_{i}=$ Difficulty index in percentage of the $i^{\text {th }}$ item

$\mathrm{n}_{\mathrm{i}}=$ Number of respondents giving incorrect answer, to $i^{\text {th }}$ item

$\mathrm{N}_{\mathrm{i}}=$ Total number of respondents to whom $\mathrm{i}^{\text {th }}$ item was administered i.e. 36 in the present study.

The discrimination index was calculated by using the method suggested by Mehta (1958). The formula by which the item discrimination index was calculated by using the given formula:

$E^{1 / 3}=\frac{\{(S 1+S 2)-(S 5+S 6)\}}{N / 3}$

Where,

$\mathrm{S} 1, \mathrm{~S} 2, \mathrm{~S} 5$ and S6 = Frequencies of incorrect answers in G1, G2, G5 and G6 groups respectively

$\mathrm{N}=$ Total number of respondents in the sample of item analysis

Based on the results of difficulty and discrimination index, final selection of items was done. Two criteria viz. item difficulty and item discrimination index had been considered for selection of items in the final format of the knowledge test. A total of 26 items were included in the final format of the knowledge test
Further, all the knowledge items were subjected to reliability and validity. Reliability in the present study was measured by splithalf method in which the format of 26 items was split into two halves of 13 each and was administered to 36 farmers. Two sets of scores were obtained and were correlated using correlation between forms (r). SpearmanBrown Prophecy Formula (also known as Spearman-Brown Prediction Formula) was used to calculate the reliability of full test and is given as under:

$R=\frac{2 r}{1+r}$

Where,

$\mathrm{R}=$ Reliability of full test

$r=$ Correlation between two half tests

For testing the internal consistency of the test, Cronbach's alpha $\left({ }^{\alpha}\right)$ was calculated given by the formula:

$\alpha=\frac{N \times c}{v+(N-1) \times c}$

Where,

$\mathrm{N}=$ Number of items.

$\mathrm{c}=$ Average covariance between item-pairs.

$\mathrm{v}=$ Average variance.

The validity of the knowledge test was established through Aiken's Validity (or V) coefficient given by Aiken (1985). For calculating the Aiken's V coefficient, all 26 items of the knowledge test were rated by 30 experts of the field. The experts were requested to judge the items on the scale of score 1 to 5,1 for the invalid and 5 for the highly valid item. The scores given by experts were designated as ' $r$ '. The score given by expert for every single item was converted to ' $S$ ' by subtracting the obtained score with 
lowest obtainable score for that item $(S=r$ lowest score). Having computed ' $S$ ', the Aiken's V coefficient can be calculated with the following formula:

$V=\frac{\sum s}{\{n(c-1)\}}$

Where,

$\mathrm{n}=$ number of experts

$\mathrm{c}=$ maximum obtainable score

Further, the content validity of the test was also assured.

\section{Results and Discussion}

\section{Selection of items for the test}

The responses were collected for 102 items based on knowledge regarding organic waste management from 36 respondents. For selection of items in the final format of the knowledge test, two criteria viz. item difficulty and item discrimination index had been considered. The underlying assumption in the statistics of item difficulty was linearly related to the level of individual's knowledge about organic waste management. When a respondent gave the correct answer to an item, it was assumed (Coombs, 1950) that the item is less difficult than his ability to cope with it. In the present study items with difficulty index ranging from 30 to 80 and discrimination index ranging from 0.30 to 0.55 were included in the final format of the knowledge test as described by Mehta (1958).According to this procedure, 26 items were selected for the final format of knowledge test on organic waste management and is given in table 1 .

\section{Reliability of the knowledge test}

Reliability is the accuracy or precision of a measuring instrument (Kerlinger 1964).
Reliability in the present study was measured by split-half method. The coefficient of correlation between forms was fond to be (r) 0.86 . This correlation coefficient produces the reliability of the test. These coefficients underestimates the reliability of full-length measure which provides a larger sample of the content domain and also tend to produce a wider range of scores, both of which have the effect of raising the reliability estimates. Hence, the above coefficient needs to be corrected to give the stepped-up reliability of the whole measure or to give the reliability of the full-length test (R). Therefore, SpearmanBrown Prophecy Formula (also known as Spearman-Brown Prediction Formula) was used. It is formula which relates the psychometric reliability of a test to the test length and has been used by the psychometricians to predict the reliability of a test after changing the test length. The value of $\mathrm{R}$ was found to be 0.927 . The internal consistency of the test was calculated using Cronbach's alpha $\left({ }^{\alpha}\right)$ and the value was calculated to be 0.828 , testifying the internal consistency of the knowledge test. All the coefficients were found to be significant at one per cent level of significance. Hence the knowledge test constructed was highly stable and reliable.

\section{Validity of the knowledge test}

The validity of the knowledge test was established through Aiken's Validity (or V) coefficient given by Aiken (1985) and the results are presented in table 2. All the coefficients were found to be significant at five percent and one per cent level of significance.

Hence the knowledge test constructed was highly stable and valid. Content validity of the test was also assured. Content validity means representativeness of the content of a measuring instrument. 
Table.1 Indices of difficulty and discrimination for items included in the final format of knowledge test

\begin{tabular}{|c|c|c|c|}
\hline S. No. & Knowledge Item & Difficulty Index & Discrimination Index \\
\hline \multicolumn{4}{|c|}{ A. Agriculture Waste Management } \\
\hline 1. & Which machine is used to mulch stubbles in soil? & 50.00 & 0.67 \\
\hline 2. & How many days are required to compost straws in field? & 72.22 & 0.33 \\
\hline 3. & Which bio-product can be cultivated by using straw, stubbles and animal manure? & 66.67 & 0.33 \\
\hline 4. & $\begin{array}{l}\text { Electricity from the straws and stubbles can be produced with the help of which of } \\
\text { the following processes? }\end{array}$ & 75.00 & 0.42 \\
\hline 5. & What is the fine per acre for illegal burning of crop residues? & 36.11 & 0.35 \\
\hline \multicolumn{4}{|c|}{ B. Household Waste Management } \\
\hline 6. & What is waste recycling? & 33.33 & 0.50 \\
\hline 7. & What is the difference between organic and inorganic waste? & 33.33 & 0.50 \\
\hline 8. & How much time is taken by kitchen waste composting machine to prepare compost? & 69.44 & 0.48 \\
\hline 9. & Which of the following method is best suited for disposing human excreta? & 58.33 & 0.48 \\
\hline 10. & How can you manage used tea leaves? & 66.67 & 0.35 \\
\hline \multicolumn{4}{|c|}{ C. Livestock Waste Management } \\
\hline \multicolumn{4}{|c|}{ i. Composting } \\
\hline 11. & What is the ideal time for filling the whole tank in NADEP composting? & 55.56 & 0.50 \\
\hline 12. & Roof/shed is necessarily required in which composting method? & 61.11 & 0.42 \\
\hline 13. & What is the particle ideal particle size for composting organic waste? & 76.11 & 0.42 \\
\hline 14. & What should be the depth of compost pit? & 66.67 & 0.55 \\
\hline 15. & What is the ideal size of heap for composting organic waste by heap method? & 72.22 & 0.33 \\
\hline \multicolumn{4}{|c|}{ ii. Vermicomposting } \\
\hline 16. & How much time is required for vermicompost to get ready? & 74.44 & 0.50 \\
\hline 17. & What is the optimal temperature range for earthworms? & 35.00 & 0.50 \\
\hline 18. & What is the capacity of a standard vermicomposting bed? & 35.00 & 0.42 \\
\hline 19. & What other items are required along with livestock waste to make vermicompost? & 72.22 & 0.57 \\
\hline 20. & What is vermiwash? & 55.56 & 0.33 \\
\hline 21. & Which of the following is the major use of vermiwash? & 66.67 & 0.33 \\
\hline \multicolumn{4}{|c|}{ iii. Biogas Production } \\
\hline 22. & Biogas can be used for? & 78.89 & 0.33 \\
\hline 23. & What waste materials are required for production of biogas? & 78.89 & 0.33 \\
\hline 24. & What is the starter culture used in biogas production? & 47.22 & 0.25 \\
\hline 25. & $\begin{array}{l}\text { What is the minimum distance to be maintained while constructing the biogas plant } \\
\text { near water bodies to prevent contamination? }\end{array}$ & 73.33 & 0.50 \\
\hline 26. & Which machine is used to convert biogas into electricity? & 73.33 & 0.33 \\
\hline
\end{tabular}

Table.2 Aiken's V coefficients for knowledge test items

\begin{tabular}{|l|c|c|c|}
\hline Item No. & Aiken's V Coefficient & Item No. & Aiken's V Coefficient \\
\hline $\mathbf{1}$ & $0.81^{*}$ & 14 & $0.88^{* *}$ \\
\hline $\mathbf{2}$ & $0.82^{*}$ & 15 & $0.81^{*}$ \\
\hline $\mathbf{3}$ & $0.80^{*}$ & 16 & $0.85^{*}$ \\
\hline $\mathbf{4}$ & $0.83^{*}$ & 17 & $0.86^{*}$ \\
\hline $\mathbf{5}$ & $0.85^{*}$ & 18 & $0.83^{*}$ \\
\hline $\mathbf{6}$ & $0.91^{*}$ & 19 & $0.80^{*}$ \\
\hline $\mathbf{7}$ & $0.87^{*}$ & 20 & $0.86^{*}$ \\
\hline $\mathbf{8}$ & $0.83^{*}$ & 21 & $0.86^{*}$ \\
\hline $\mathbf{9}$ & $0.86^{*}$ & 22 & $0.93^{*}$ \\
\hline $\mathbf{1 0}$ & $0.88^{*}$ & 23 & $0.86^{*}$ \\
\hline $\mathbf{1 1}$ & $0.88^{*}$ & 24 & $0.83^{*}$ \\
\hline $\mathbf{1 2}$ & $0.82^{*}$ & 25 & $0.83^{*}$ \\
\hline $\mathbf{1 3}$ & $0.85^{*}$ & 26 & $0.83^{*}$ \\
\hline
\end{tabular}

$(*$ significant at $p<0.05, * *$ significant at $p<0.01)$ 
Table.3 Knowledge test on organic waste management

\begin{tabular}{|c|c|c|c|}
\hline S. No. & Item & Correct & Incorrect \\
\hline \multicolumn{4}{|c|}{ A. Agriculture Waste Management } \\
\hline 1. & $\begin{array}{l}\text { Which machine is used to mulch stubbles in soil? } \\
\text { a. Mulcherb.Baler } \\
\text { c. Super SMS d. Happy Seeder }\end{array}$ & & \\
\hline 2. & How many days are required to compost straws in field? (Ans: 45 days) & & \\
\hline 3. & $\begin{array}{l}\text { Which bio-product can be cultivated by using straw, stubbles and animal manure? (Ans: } \\
\text { Mushroom) }\end{array}$ & & \\
\hline 4. & $\begin{array}{l}\text { Electricity from the straws and stubbles can be produced with the help of which of the } \\
\text { following processes? } \\
\text { a. Biogas production b.Composting } \\
\text { c. Vermicomposting d.Burning }\end{array}$ & & \\
\hline 5. & $\begin{array}{l}\text { What is the fine per acre for illegal burning of crop residues? } \\
\text { (Ans: Upto Rs. 2,500/acre) }\end{array}$ & & \\
\hline \multicolumn{4}{|c|}{ B. $\quad$ Household Waste Management } \\
\hline 6. & What is waste recycling? & & \\
\hline 7. & What is the difference between organic and inorganic waste? & & \\
\hline 8. & $\begin{array}{l}\text { How much time is taken by kitchen waste composting machine to prepare compost? } \\
\text { (Ans: } 24-72 \text { hours) }\end{array}$ & & \\
\hline 9. & $\begin{array}{l}\text { Which of the following method is best suited for disposing human excreta? } \\
\text { a. Landfill b. Incineration } \\
\text { c. Septic tank disposal d. Discarding in water bodies }\end{array}$ & & \\
\hline 10. & $\begin{array}{l}\text { How can you manage used tea leaves? } \\
\text { (Ans: Composting, Preparing liquid manure) }\end{array}$ & & \\
\hline \multicolumn{4}{|c|}{ C. Livestock Waste Management } \\
\hline \multicolumn{4}{|c|}{ Composting } \\
\hline 11. & What is the ideal time for filling the whole tank in NADEP composting? (Ans: 24 hours) & & \\
\hline 12. & Roof/shed is necessarily required in which composting method? (Ans: NADEP) & & \\
\hline 13. & What is the particle ideal particle size for composting organic waste? (Ans: $10-15 \mathrm{~cm}$ ) & & \\
\hline 14. & What should be the depth of compost pit? (Ans: $3 \mathrm{ft}$ or $1 \mathrm{~m})$ & & \\
\hline 15. & $\begin{array}{l}\text { What is the ideal size of heap for composting organic waste by heap method? [(Ans: } 2 \mathrm{~m} \\
(\mathrm{~W}), 1.5 \mathrm{~m}(\mathrm{H}), 2 \mathrm{~m}(\mathrm{~L})]\end{array}$ & & \\
\hline \multicolumn{4}{|c|}{ Vermicomposting } \\
\hline 16. & $\begin{array}{l}\text { How much time is required for vermicompost to get ready? } \\
\text { a. } 2-3 \text { months b. } 3-4 \text { months } \\
\text { c. } 4-5 \text { months d.5- } 6 \text { months }\end{array}$ & & \\
\hline 17. & What is the optimal temperature range for earthworms? (Ans: $15-35^{\circ} \mathrm{C}$ ) & & \\
\hline 18. & $\begin{array}{l}\text { What is the capacity of a standard vermicomposting bed? } \\
\text { (Ans: 600kg waste) }\end{array}$ & & \\
\hline 19. & What other items are required along with livestock waste to make vermicompost? & & \\
\hline 20. & What is vermiwash? & & \\
\hline 21. & $\begin{array}{l}\text { Which of the following is the major use of vermiwash? } \\
\text { a. Bio-pesticide b.Vermiculture } \\
\text { c. Treating earthworms d. Treating vermicompost }\end{array}$ & & \\
\hline \multicolumn{4}{|c|}{ Biogas Production } \\
\hline 22. & $\begin{array}{l}\text { Biogas can be used for? } \\
\text { (Ans: Lighting, Cooking, Electricity production, etc.) }\end{array}$ & & \\
\hline 23. & $\begin{array}{l}\text { What waste materials are required for production of biogas? } \\
\text { (Ans: Animal manure, Agriculture residues, Sewage sludge) }\end{array}$ & & \\
\hline 24. & $\begin{array}{l}\text { What is the starter culture used in biogas production? } \\
\text { (Ans: Animal dung) }\end{array}$ & & \\
\hline 25. & $\begin{array}{l}\text { What is the minimum distance to be maintained while constructing the biogas plant near } \\
\text { water bodies to prevent contamination? } \\
\text { a. } 5 \mathrm{~m} \text { b. } 10 \mathbf{~ m} \\
\text { c. } 15 \mathrm{~m} \mathrm{~d} .20 \mathrm{~m}\end{array}$ & & \\
\hline 26. & $\begin{array}{l}\text { Which machine is used to convert biogas into electricity? } \\
\text { (Ans: Electric generator) }\end{array}$ & & \\
\hline
\end{tabular}


In the final selection of items, care was taken to include items covering the entire universe of relevant behavioral aspects of respondents with respect to knowledge about the organic waste management and it has been assumed that the scores obtained by administering the tests measures knowledge of the respondents as it was intended. The final knowledge test is given in table 3 .

\section{Utility and Conclusion}

As long as there is life on earth, waste organic waste will be produced and managing that waste will be a real challenge. The test can serve to be tool to ascertain the knowledge of stakeholders regarding management of organic waste. The test can be used by researchers, institutes and organizations for ascertaining the knowledge of respondents under study. The test can be used for estimating the net knowledge deficit regarding organic waste management that will thrust policy making in this direction. Assessment of knowledge gain and knowledge enhancing interventions can be made using the test. The test items presented in the test are simple in nature and easily understandable making the test handy to use.

\section{References}

Aiken, L.R. (1985). Three Coefficients for Analyzing the Reliability and Validity of Ratings. Educational and Psychological Measurement. 45: 131-42 Coombs, C.H. (1950). The concept of reliability and homogeneity. Educational

Measurement. 10: 33-39.

Psychological

Edwards, A.L. (1957). Techniques of Attitude Scale Construction. Irvington Publishers, Inc. New York.

Garret, H. E. (1966). Statistics in Psychology and Education. Hyderabas, International Book Bureau.

Gronlund, N. E. (1970). Measurement and Evaluation in Teaching. New York, Macmillan Publishing Co.

Kerlinger, F. (1964). Foundations of Behavioural Research. New York, Holt.

Mehta, P. (1958). A study of Communication of Agricultural Information and Extent of Distortion occurring from District to Village Level Workers in Selected I.A.D.P. of Udaipur, Rajasthan. PhD thesis. Udaipur Agricultural University, Rajasthan.

Ministry of Drinking Water and Sanitation, India. (2015). Solid and Liquid Waste Management in Rural Areas. Retrieved as

https://mdws.gov.in/sites/default/files/Pr imer\%20SLWM.pdf on 22-03-2019.

Singh, A. (2019). Development of a needbased and effective mobile app for promoting organic waste management among dairy farmers. Thesis, MVSc. ICAR-Indian Veterinary Research Institute, Izatnagar, p 138.

Vyas, L. and Maheshwari, S. (2009). Knowledge of the tribal women of Udaipur district regarding vermiculture technology. Tribe, 39: 68-91.

\section{How to cite this article:}

Amandeep Singh, Rupasi Tiwari, Pratikshya Panda, Pragya Joshi and Triveni Dutt. 2019. Development and Standardization of Knowledge Test for Organic Waste Management. Int.J.Curr.Microbiol.App.Sci. 8(08): 1443-1449. doi: https://doi.org/10.20546/ijcmas.2019.808.168 